\title{
Ricardo Palma, el "Bibliotecario mendigo": amor al libro a través de sus cartas
}

\author{
Manuel Pantigoso Pecero \\ Universidad Ricardo Palma \\ mpantigoso@urp.edu.pe
}

\section{Resumen}

Este trabajo complementa otros que se refieren a la relación y actuación de Ricardo Palma en la Biblioteca Nacional, a propósito del saqueo durante la Guerra con Chile. Aparecen todos los esfuerzos del "Bibliotecario mendigo" al solicitar y recibir donaciones de libros de distintos países. El estudio incluye también las consecuencias del discurso de González Prada en el Politeama y la respuesta de Palma, durante una época de divisiones y enfrentamientos en la cual participaron, inclusive, Haya de la Torre y Mariátegui, que rechazaron el calificativo de decadente y colonialista contra Palma. También está en el trabajo las intervenciones de Clemente Palma, hijo de don Ricardo. Al final incluimos algunas ideas sobre el libro y su relación con el desarrollo del hombre y la cultura.

Palabras clave: Biblioteca, Palma, González Prada, Guerra con Chile, Colonialismo, libro, cultura.

\begin{abstract}
This work complements others that discuss about the relationship and performance of Ricardo Palma in the National Library, related to plunder during the war with Chile. All the efforts of the "beggar Librarian" comes up at the moment of asking for donations of books from different countries. The study also includes the consequences of González Prada's speech in the Politeama and the response of Palma, during a time of divisions and clashes in which even Haya de la Torre and Mariátegui participated, the ones who rejected the title of decadent and colonialist against Palma. It is also present the interventions of Clemente Palma, Don Ricardo's son. In the end we show some ideas about the book and its relationship with the development of man and culture.
\end{abstract}

Keywords: library, Palma, González Prada, War with Chile, Colonialism, book, culture. 
Manuel Pantigoso Pecero, poeta, crítico literario y de arte, dramaturgo y maestro universitario, promotor cultural y periodista. Doctor en Literatura y Filología y Doctor en Educación. Doctor Honoris Causa de la Universidad Ricardo Palma. Profesor Emérito de la UNMSM. Miembro de la Academia Peruana de la Lengua. Director de la Oficina Central de Extensión Cultural y Proyección Social de la U.R.P. y Presidente del Instituto Ricardo Palma. 
Ricardo Palma, el "Patriarca de las Letras Peruanas" (Lima, 7 de febrero de 1833- Lima, 6 de octubre de 1919) tuvo otro apelativo relevante: "El bibliotecario mendigo". Sobre su significación existen esclarecidos estudios de Teodoro Hampe Martínez, Guillermo Durand Flores, Roy Tanner, Vicente Revilla, entre otros. Al respecto, y siguiendo su ruta epistolar ${ }^{1}$, hemos encontrado otras vetas no estudiadas suficientemente sobre el descollante esfuerzo que le significó a Palma la reconstrucción de la Biblioteca Nacional, asolada con motivo de la Guerra con Chile.

\section{Una imagen distorsionada y la verdadera impronta del tradicionista}

Ha quedado grabado en el imaginario popular una imagen de Ricardo Palma que lo muestra como un abuelo amable de aspecto jocundo, con gruesos lentes de carey por donde asoman unos ojillos chispeantes y hurgadores capaces de revisar minuciosamente pesados infolios y papeles antiguos. Recordemos que otro enfoque, sobre la base de la oposición pasado-presente, lo tipificaría como retrógrado. Esta calificación rondó al autor de las Tradiciones Peruanas desde las últimas décadas del siglo pasado. Sin embargo, él, lejos de sentirse un conservador, se consideraba más bien un liberal de antigua data, un progresista a carta cabal y, además, una persona que amaba profundamente a su patria. Y todo ello lo podía demostrar. Ahí estuvo, por ejemplo, su presencia en las operaciones militares durante el desembarco en Guayaquil (1859), así como su participación en el Combate del 2 de Mayo y en la defensa de Miraflores, en 1866 y 1881 respectivamente.

1 En este trabajo recogemos la valiosa información contenida en el Epistolario General (Tomos: 1846-1891; 1892-1904; 1905-1919) editados por la Editorial Universitaria de la Universidad Ricardo Palma, 2005-2006. 


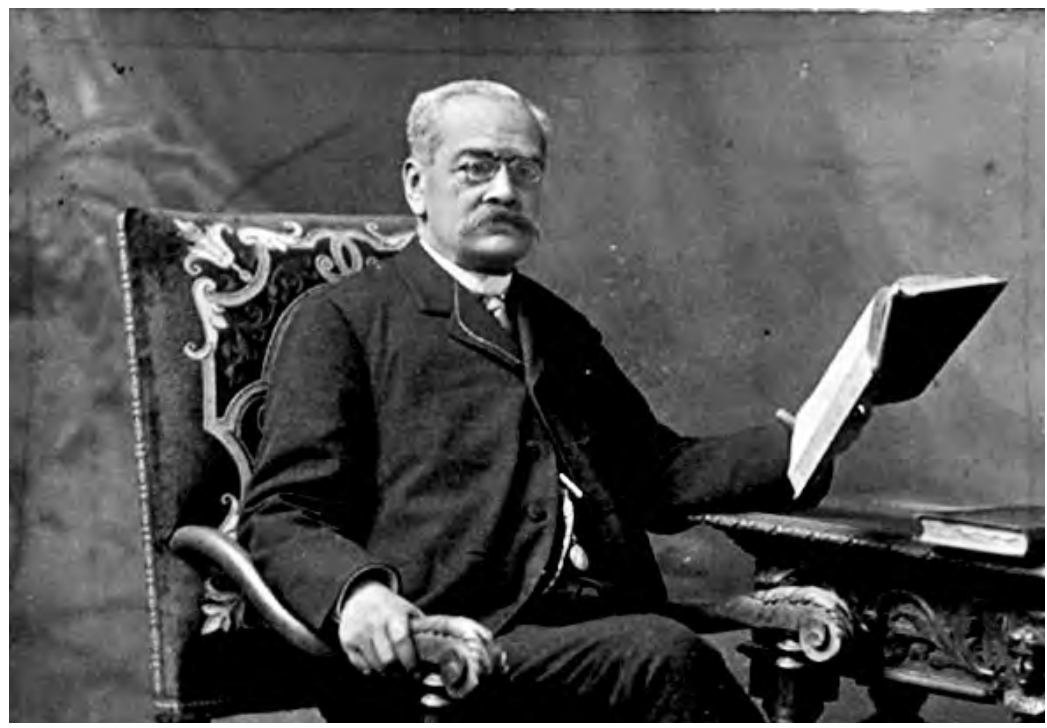

Fig. 1 .

Ricardo Palma

Fuente: http://www.asale.org/noticias/lima-en-la-pluma-de-ricardo-palma

Pero Palma también podía exhibir otros decididos "combates", como el que ahora nos ocupa: el librado para reconstruir la Biblioteca Nacional luego de la Guerra con Chile, a la cual el ardiente patriota se entregó en cuerpo y alma con la noble tarea de recuperar, mediante libros donados, el reservorio espiritual de la nación. Se estima que fueron extraídos más de cuarentaicinco mil volúmenes, quedando solo poco menos de tres mil, la mayoría de ellos sobre materias teológicas. Ante este latrocinio, él movilizó sus influencias de laureado escritor por todo el mundo hispánico a fin de ganar para su causa la benevolencia de hombres de letras, políticos, intelectuales, artistas, historiadores que, sensibilizados por los pedidos del egregio tradicionista, enviaron sus aportes bibliográficos y, además, ampliaron la cadena de solidaridad con otros amigos a favor de la reactivación de la biblioteca ultrajada. 


\section{Empieza la historia verdadera}

La historia pudo haber sido otra. Poco faltó para que el escritor viajara a Buenos Aires para incorporarse al cuerpo de redacción del prestigioso diario La Prensa, al recibir una tentadora oferta económica. Esta propuesta coincidiría con la desocupación de Lima por las fuerzas chilenas y con el advenimiento del gobierno del general Miguel Iglesias, el 23 de octubre de 1883. El mandatario le pidió, entonces, que tomase las riendas de la Biblioteca Nacional, otorgándole todas las prerrogativas para el desempeño de sus funciones. La conversación sostenida entre Palma y José Antonio de Lavalle, escritor y ministro de Gobierno, fue muy elocuente:

Abandone usted su propósito de viaje a Buenos Aires, y restaure la Biblioteca Nacional. Para cualquier otro la empresa sería imposible, pues en las arcas fiscales no hay dinero ni para atender a los gastos menudos más premiosos. Utilice usted, en beneficio del país, su prestigio literario en el extranjero y sus relaciones personales con hombres eminentes de cada nación americana y de España. - ¿Me propone usted, le interrumpí, que me convierta en bibliotecario mendigo?- Justamente, continuó Lavalle. Pida usted limosna para beneficiar a su patria. (Palma, 1912: 4)

La misiva dirigida al eminente filólogo y escritor español Marcelino Menéndez y Pelayo puede dar testimonio de la forma como Palma dedicó todo su empeño para sacar a los peruanos de la oscuridad y del pesimismo de la derrota, y proyectar en sus compatriotas el optimismo de la cultura a través de los libros, pan de la sensibilidad y la inteligencia:

Un bibliotecario mendigo se dirige, pues, al ilustre literato, para pedirle la limosna de sus obras, y que avance su caridad hasta solicitar de sus esclarecidos compañeros, en 
las Academias de la Historia y de la Lengua, contribuyan a la civilizadora fundación encomendada, más que a mis modestas aptitudes, a mi entusiasmo y perseverancia. (2005: 255).

\section{Un soldado de la pluma}

Esta misión altruista y patriótica tuvo sus prolegómenos a partir, sin duda, de los infaustos sucesos ocurridos en la Batalla de Miraflores. Su casa fue presa de las llamas y con ella sus libros y manuscritos. Raúl Porras Barrenechea diría: "Uno de los más graves episodios de la vida de Palma y que dejó más penosa huella en su espíritu fue la de la pérdida de su biblioteca de más de cuatro mil volúmenes, incendiada por la soldadesca chilena en enero de 1881"2. En el fuego se quemaron, entre otros documentos y papeles, sus memorias relativas a los cuatro años de gobierno del presidente Balta, de quien había sido secretario, así como su novela Los Marañones y las obras sobre Monteagudo, Sánchez Carrión y Bolívar.

En el despojo de libros de la Biblioteca Nacional, el tradicionista se comportó como un "soldado de la pluma". El 26 de enero de 1881 los chilenos exigieron al coronel Manuel de Odriozola -entonces director de la Biblioteca Nacional- la entrega de las llaves, principiándose desde ese día a encajonarse los libros, los cuales eran llevados en carretillas para ser embarcados con destino a Santiago. En su calidad de subdirector honorario de dicho establecimiento -cargo recibido en noviembre de 1880 del presidente Nicolás de Piérola-, Palma se prodigó al máximo aun a costa de su salud y seguridad física. Tuvo conversaciones con el alcalde limeño Rufino Torrico y con los ministros plenipotenciarios de Francia y Estados Unidos para impedir

2 Félix Álvarez Brun, 2000: 13-14. 


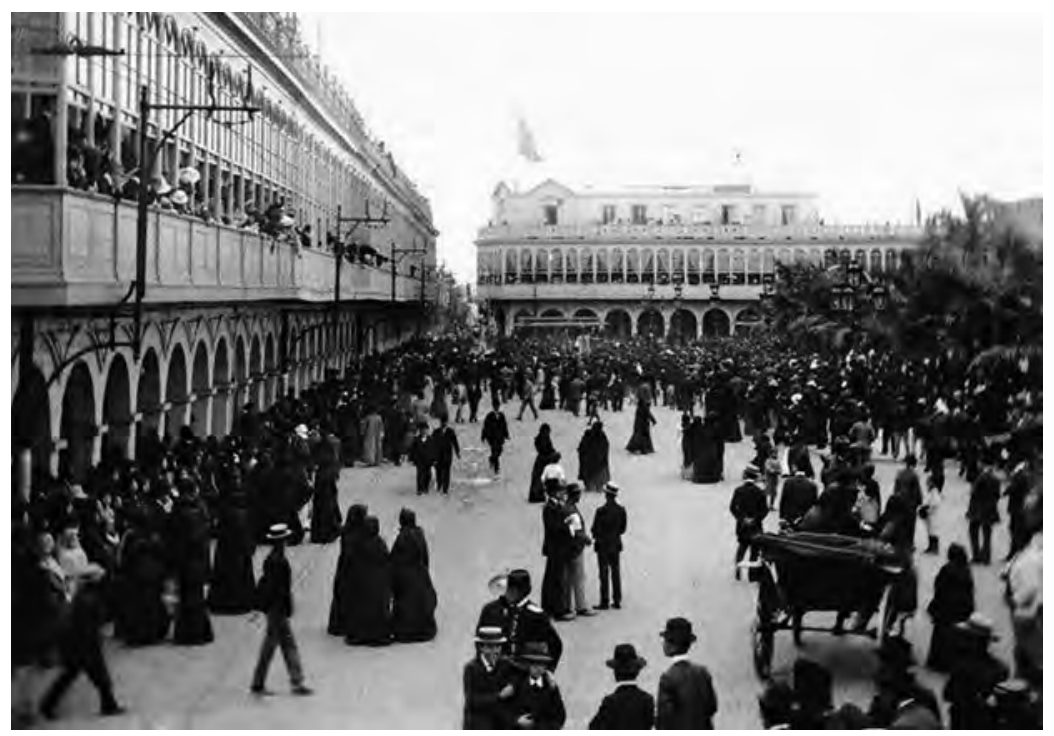

Fig. 2.

Lima antigua

Fuente: http:/archivo.elcomercio.pe/sociedad/lima/fotos-imagenes-lima-antiguaproyecto-que-busca-mostrar-pasado-ciudad-noticia-148517 I

el atentado; inclusive, su carta de protesta fue publicada en el diario chileno "La Actualidad". El general chileno Lynch, que por el mes de mayo estaba en Lima como autoridad superior, dispuso su inmediata prisión, permaneciendo doce días a bordo de un transporte chileno; sin embargo, gracias a las gestiones de los ministros de Francia y Brasil, fue puesto en libertad.

\section{Labor del Bibliotecario Mendigo}

A fines de 1883, el gobierno del Perú le entregó a Palma la dirección de la Biblioteca Nacional. Alborozado, diría entonces (2005: 255): "El país ha acogido con entusiasmo el propósito $y$, en menos de quince días, he recibido donativos por más de diez mil volúmenes". 
Usando sus vínculos amicales con el presidente chileno Domingo Santa María, obtuvo la devolución del cuadro "Los funerales de Atahualpa" y dos cajones con manuscritos. El propio mandatario sureño respondería:

No se ha equivocado usted al creer, como me lo dice en su carta de 20 de febrero, que tendría buena voluntad para devolverle a la Biblioteca de Lima los libros que de ahí pudieron sacarse en un momento de ardor bélico (...). A Dios gracias, los tiempos bonancibles vuelven, y usted dejará de andar con una espada al cinto y volverá a tomar la pluma para escribir, como siempre, sabrosos y bien aliñados artículos. Le adjunto la lista de los libros que le envío por el vapor Chile que zarpa mañana de este puerto. Pruébele esta remesa mi deseo de complacer a usted y de hacer fructuosa la tarea que se ha impuesto ${ }^{3}$.

Palma empezaría a trabajar con prisa para que la inauguración se realizase el 28 de julio de 1884. Nada dejaba al azar, era enérgico y claro pues su pedido era de interés nacional, como cuando se dirigió al alcalde de la comuna limeña para pedir apoyo en la encuadernación de algunos lotes de libros. Lo hace con su característico tono festivo:

¿Sospecha usted, querido amigo lo que de usted y de sus ilustrados compañeros de Municipio pretendo? Siempre gusté, entre las cosas claras, del agua; y, entre las espesas, del chocolate. Le hablaré claro y espeso; le hablaré al alma y al bolsillo. Pues señor: quiero que la Municipalidad se encargue de vestirme siquiera mil quinientos volúmenes, que andan por ahí los pobrecitos desnudos que dan lástima. (2005: 257).

3 “Nuevo asedio al 'Bibliotecario mendigo': Ricardo Palma en la Biblioteca Nacional”, artículo de Teodoro Hampe Martínez, publicado en la revista Aula Palma $\mathrm{N}^{\circ}$ X, Lima, Universidad Ricardo Palma, 201 1: 211. 


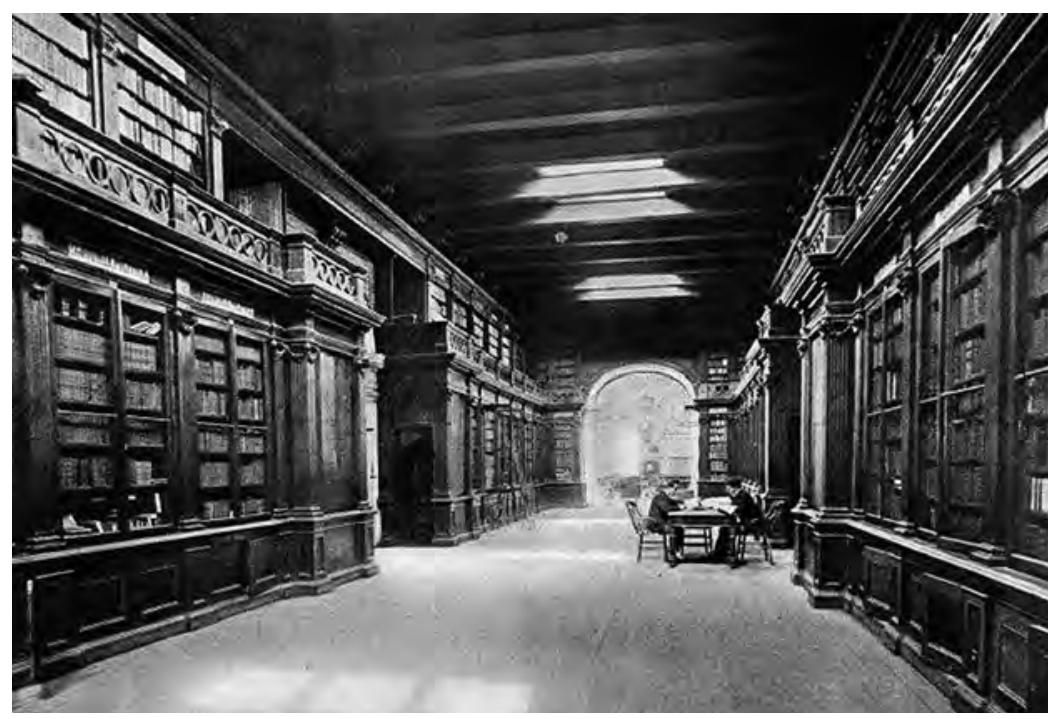

Fig.3.

\section{Biblioteca Nacional}

Fuente: https://peru.com/actualidad/mi-ciudad/lima-mira-como-lucian-principalespuntos-ciudad-antes-1910-fotos-noticia-222079-712748? foto $=8$

Al aproximarse la fecha de la reapertura la Biblioteca contaba con más de veinte mil volúmenes. Países como Ecuador, Argentina, Uruguay, Venezuela, Colombia, México, a través de afamados hombres de la cultura, hicieron sus aportaciones editoriales. Palma, que contaba con el apoyo decidido del general Iglesias, ${ }^{4}$ se sentía entusiasmado por la obra realizada como lo manifiesta en la siguiente misiva:

4 Gran estimación le tenía Palma al controvertido general Iglesias como se aprecia en el siguiente epitafio, escrito en su memoria: "Era el deber su consigna;/era el trabajo su emblema,/ era la patria su culto/ y era el honor su bandera./ Nunca nublaron dobleces/ el azul de su conciencia,/ ni el huracán de la envidia/ rindió su altiva cabeza./ La batalla de la vida/ peleó como noble atleta,/ sin arredrarlo peligros/ ni envanecerlo grandezas./ iDuerme en paz! y que tu espíritu,/ allá en la región eterna,/ alcance para tu patria/ el bien que tu patria anhela" (en Obra poética de Ricardo Palma, compilada por Merlín Compton, 2000: 512). 
Para mí se ha hecho cuestión de honra y de orgullo dar al país Biblioteca con la mitad siquiera de los volúmenes que antes tuvo. Este será el timbre que deje a mis retoños. Ya faltan solo dos meses para ver realizada esta antigua aspiración mía. Después de julio no me hará mella que cualquier Gobernante me destituya y nombre en mi lugar al Murciélago, a don Felipe Paz-Soldán o al clerizonte La Rosa. Me quitarán el empleo: pero no la gloria de haber formado Biblioteca (2005: 265).

De estas últimas palabras se desprenden algunas rencillas que pudo haber tenido con algunos personajes que discutían su fama, a los que les respondía:
¿Tienes talento? Exhíbelo altanero
para que el mundo su sanción te preste:
el talento ignorado vale un cero...
de talentos inéditos hay peste.
El mérito se impone y aun se aclama, mal que le pese al envidioso anhelo:
caben todos los hombres en la fama, como todos los astros en el cielo ${ }^{5}$.

La Biblioteca, con Palma como director, estaba en ascenso. El acelerado ingreso de nuevos libros continuaba en aumento gracias a esa positiva gestión epistolar con escritores y políticos amigos. Las innumerables cartas cursadas por esos años son prueba fehaciente. Algunos pedidos de libros pudieron rayar en la descortesía si es que el destinatario no fuese el amigo que entiende y apoya esta cruzada cultural del apasionado "Bibliotecario mendigo", que cumplía cabalmente un mandato nacional. En la siguiente carta, por ejemplo, pide sin remilgos textos sobre literatura mexicana:

5 "A un envidioso". Merlin Compton 2000: 511. 
Ya que tan benevolente me brinda usted su amistad y servicios, prestándose a ayudarme, con espíritu de patriótico americanismo, le ruego se moleste en ver, en mi nombre, a Altamirano y Guillermo Prieto y pedirles sus libros. De Mateos solo tengo un romance -El cerro de la campana- y de Peza nada he recibido. Desearía también las obras del popular Fernando Calderón, muerto hará 20 años. De D. Anselmo de la Portilla, padre del joven amigo mío, nada tengo. De Agustín Cuenca, Chavero, Agapito Silva y las poetisas mexicanas tampoco tiene la biblioteca un solo libro. Le recomiendo me consiga las obras de Ester Tapia y de Isabel Landázuri, así como unas Tradiciones sobre las niñas de México escritas por un D. Pedro Castera (...) Deseo vivamente conocer el libro de Ud. sobre escritores contemporáneos de México. No olvide enviármelo (...) Ya ve Ud. amigo Agüeros, cuán llano y poco ceremonioso soy; pues lo abrumo con encargos y peticiones, amén que a sus confidencias correspondo haciéndole las mías individuales (2005: 284-285).

De modo general, Palma fue un devoto cumplidor de las normas de la comunicación social que exigen, por cortesía, el agradecimiento a aquellos que desinteresadamente contribuyen con su causa. Con atinada prosa respondía y agradecía a sus amigos, alentándolos de paso en su trabajo literario o de otra índole. Paralelamente continuaba escribiendo sus famosas tradiciones, pues su vena artística nunca se acalló. Rubén Darío -el genial vate de Prosas profanas y Cantos de vida y esperanzadiría en un fragmento de su "Fotograbado", donde narra su visita a la biblioteca peruana, en febrero de 1888:

Es la primera figura literaria que tiene el Perú, junto con mi querido amigo el poeta Márquez, insigne traductor de Shakespeare. Y -a propósito de poetas-, en una de sus cartas me decía una vez don Ricardo: 'Yo no soy poeta'. Ante esta 
declaración, no hice sino recordar su magistral introducción de Víctor Hugo, donde aparece, formidable y aterrador, aquel ojo que, desde lo infinito, está fijo mirando a Caín, en todas partes. En cuanto a sus versos ligeros y jocosos, pocos hay que le aventajan en gracia y facilidad. Tienen la mayor parte de ellos un algo encantador, y es la nota limeña (Palma, 2005: IX).

\section{Vientos huracanados en la Biblioteca}

El ya célebre tradicionista descansaba su gloria (al menos en un sentido social y cultural) en el renacimiento personalísimo de ese rico venero de la tradición que conserva la herencia espiritual del Perú. En su norte de vida estaba también la reconstrucción de la Biblioteca que cumpliría denodadamente, sin dejar de lado su actividad política y sus posibles candidaturas para tomar una curul en el Congreso.

En el año de 1885, Lima era un campo de batalla entre los adeptos de Iglesias y de Cáceres, que significó la caída del primero y la instalación en el gobierno del segundo. Palma sabía que tiempos difíciles se aproximaban y supo sopesar las dificultades con prudencia:

El nuevo gobierno no me molestará en mi puesto de bibliotecario; pero temo que retirando toda protección a la Biblioteca, me ponga en el compromiso de renunciar. La Biblioteca (creación del gobierno que cayó) no es simpática a los hombres de hoy, si bien el bibliotecario les dispensa, a más no poder, consideraciones personales (2005: 276).

Un primer aldabonazo llegaría en las postrimerías de ese año cuando Manuel Bravo, exjefe del Archivo Nacional, pidió su reposición. Recordemos que por decreto del 2 de noviembre de 1883 la Biblioteca y el archivo se refundieron en un solo 
establecimiento del que Palma era director. De manera airada, pero justa, envió una misiva de protesta a Manuel Tovar, ministro de Estado en los ramos de Instrucción y Justicia, expresándole que tal reposición sería un desaire a sus esfuerzos y dedicación bibliotecaria. He aquí el meollo del asunto contado por el propio tradicionista:

Cuando el enemigo invasor destruyó biblioteca y archivo, en marzo de 1881, era yo subdirector honorario del primer establecimiento. Entonces redacté una protesta, que suscribió el señor Odriozola, la cual se depositó en la legación de Estados Unidos y se publicó en muchos periódicos del extranjero. Esa protesta nos acarreó serias persecuciones de Chile, que se tradujo para mí en una prisión de doce días a bordo de una nave chilena, en el Callao. Invitamos, por entonces, al señor Bravo para que también protestase; y él, que vio impasible realizarse la destrucción del establecimiento de que era jefe, sin protestar ante el mundo civilizado, aspira hoy, en que el país tiene archivo debido a mis esfuerzos, a arrebatarme mi carácter de Jefe (2005: 289).

Con respuesta lacónica, Tovar respondería de la siguiente forma (Lima, 19 de diciembre de 1885): "Conténtese el director oficiante, que el gobierno se halla satisfecho de los servicios que presta en la Biblioteca y Archivo Nacional".

Por esos días, Manuel González Prada pidió cortésmente a Palma las traducciones que hiciera a la poesía de Enrique Heine, pues iba a realizar sobre este notable poeta alemán una conferencia en el Ateneo de Lima, donde sería incorporado. El autor de Verbos y Gerundios declaró encantado: "Pídeme usted, y hácelo con tan afectuosos modos, que no me deja tiempo para la excusa" (2005: 292). Traemos a la memoria este hecho porque demuestra que existía, si no amistad, alguna simpatía entre estos dos escritores que luego tomarían sentidos opuestos 
a partir del conocido Discurso del Teatro Politeama, en donde González Prada alude a Palma cuando afirma: "Los jóvenes a la obra; los viejos a la tumba".

El 3 de junio de 1886 fue ungido como presidente de la República el general Andrés Avelino Cáceres, el héroe de la Breña, cargo que se extendería hasta el 10 de agosto de 1890. Palma sabía que se aproximaban tiempos nada buenos que lo podían separar de su amada biblioteca:

El 3 del entrante tendremos Presidente Constitucional. Es muy probable que yo renuncie a mi puesto de bibliotecario o que me lo hagan renunciar; pues los hombres que van a ser gobierno son de comisura política diversa a la mía. Ya avisaré a Ud. lo que decida por el vapor próximo (2005:308).

Con el nuevo gobierno, si bien Palma continuaría como director de la Biblioteca, no recibiría ningún apoyo, como lo atestigua la siguiente misiva:

El circulillo que hoy está en el gobierno es de lo más intransigente que cabe. A mi pobre Biblioteca no le dispensan la más ligera protección, y, ¿por qué? Porque cupo a Iglesias la suerte de haber iniciado la reorganización de ella. Por lo demás, personalmente, así el General Cáceres como sus ministros me colman de atenciones cada vez que tengo precisión de acercarme a ellos. Me prometen mucho en favor de la Biblioteca y... nada cumplen. He resuelto, pues, cruzarme de brazos y que la biblioteca siga estacionaria (2005: 352).

Las pugnas políticas y la efervescencia social del país crearían por esos años un panorama desolador para las letras y los libros. Sin embargo, el escritor dejaba sentado su emblema lleno de optimismo: "Aunque nadie, ni Congreso, ni Gobierno, ni pueblo estiman mi afanosa labor bibliotecaria; yo sigo erre con erre. 
Creo que la única virtud que poseo es la de la perseverancia. Sin ser yankee, mi divisa es: iadelante!".

\section{El Discurso del Politeama y la polémica entre González Prada y Palma}

El 29 de julio de 1888 Manuel González Prada redactó un discurso ardido y vibrante, leído por un niño en el Teatro Politeama, donde estamparía las siguientes palabras:

En esta obra de reconstrucción y venganza no contemos con los hombres del pasado: los troncos añosos y carcomidos produjeron ya sus flores de aroma deletéreo y sus frutos de sabor amargo. iQue vengan árboles nuevos a dar flores nuevas y frutas nuevas! iLos viejos a la tumba, los jóvenes a la obra! (Sánchez, 1986: 371).

En otro discurso ofrecido en el Teatro Olimpo haría una alusión directa a las tradiciones de Ricardo Palma, cuya forma y estilo habían sido reproducidas por múltiples escritores del Perú y de América:

Cultivamos una literatura de transición, vacilaciones, tanteos y luces crepusculares. De la poesía van desapareciendo las descoloridas imitaciones de Bécquer; pero en la prosa reina siempre la mala tradición, ese monstruo engendrado por las falsificaciones agridulces de la historia y la caricatura microscópica de la novela (Sánchez, 1986: 65).

Como respuesta, Palma escribiría un artículo ponderado refutando la frase "iLos viejos a la tumba y los jóvenes a la obra!". Al escribirlo, no lo hizo en defensa de una causa propia sino de la concordia humana. Diría entonces:

La juventud es entusiasta e irreflexiva. La vejez, serena y razonadora. No hay bien ni progreso para la humanidad sin 
concierto armónico entre los hombres. Ni los viejos llevan en sus canas la exclusiva del error y del mal, ni los jóvenes, en sus cabellos negros, la patente del acierto y del bien (Sánchez, 1986: 412).

Escuchemos a Clemente Palma, hijo del tradicionista, narrar los entretelones de este desencuentro entre dos notables escritores del siglo XIX y de principios del XX:

Don Ricardo Palma había tenido en alta estima a González Prada y como un homenaje de aprecio a su talento le dedicó un folletito conteniendo traducciones de las poesías de Heine, que distribuyó entre los asistentes a la fiesta literaria de incorporación de González Prada al Ateneo de Lima. En 1887 preparó González Prada un discurso que tuvo gran repercusión porque era una reacción contra el pasado y se vilipendiaba en él la obra política de los forjadores de la República; en esa vibrante pieza literaria se estampaba la famosa pieza literaria "los viejos a la tumba y los jóvenes a la obra”. Palma publicó moderada crítica en la que reclamaba de González Prada mayor serenidad y ponderación para juzgar la obra de los hombres de la generación posterior a la Independencia, pues si muchos errores cometieron y muchas taras tuvieron, también hicieron buenas cosas y poseyeron méritos. Palma tenía entonces cincuenta y cuatro años y González Prada ocho o diez menos; propiamente, ni el uno representaba la vejez decrépita ni el otro la juventud ardorosa y renovadora; pero la muchachada literaria quiso ver en los dos escritores los símbolos de dos edades y de dos direcciones espirituales contrapuestas y se puso, naturalmente, al lado de González Prada, atacando con virulencia y descortesía grosera al tradicionista. Gonzáles Prada rehuyó la polémica, pero hizo que todos los gozquecillos de su traílla mordisquearan los talones de su crítico. Desde entonces González Prada fue sedimentando 
una animadversión feroz contra mi padre y que crecía con el ascensional prestigio de éste y la afirmación de su obra (Palma: 1951: XII).

\section{Palma en el análisis de las nuevas generaciones}

En un artículo nuestro dedicado al autor de las Tradiciones, titulado "El sentido del pasado y la actualidad de la lengua en las tradiciones de Palma”, veíamos cómo personajes de la talla de Haya de la Torre y de Mariátegui rechazaron los calificativos de decadente y colonialista aplicados a la obra de Palma, destacando más bien el sentido crítico y libertario presente en las Tradiciones.

Pareciera ser que la argucia del civilismo intelectual para dividir a los dos escritores más importantes del Perú, hasta ese momento, había dado sus frutos, pero la interpretación de las nuevas generaciones era diferente, como la podemos observar en estas palabras de Haya de la Torre:

Nosotros hemos rescatado a Prada, arrancándolo de los chauvinistas del civilismo para entregárselo a la nación que es el pueblo. Lo mismo haremos con Palma, y he ahí una de las tareas de ustedes: arrancarle de la interpretación civilista, librar su memoria de la maliciosa profanación del espíritu rebelde de su obra, y entregarlo también a la nación, que es el pueblo, al lado de Prada, como intelectuales revolucionarios precursores de nuestra gran causa presente ${ }^{6}$.

Por su parte, Mariátegui ha de resumir la tarea sugerida, y al referirse a la generación "futurista" de Riva Agüero, que él

6 "Mensaje para la revista Amauta Lima", carta dirigida a José Carlos Mariátegui, fechada en Londres el 2 de noviembre de 1926, en "Amauta" $N^{\circ} 4$, Lima, diciembre de 1926. 


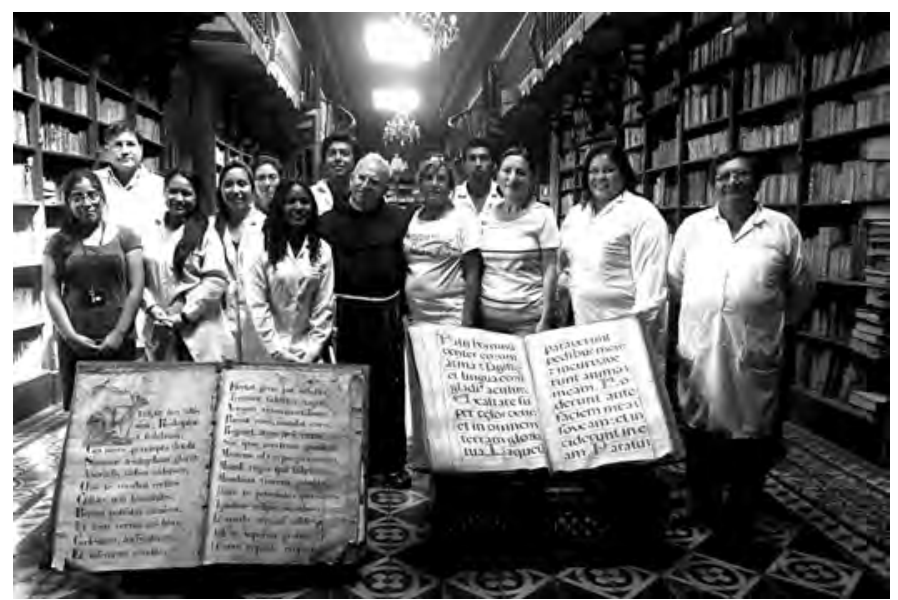

Fig. 4 .

Biblioteca San Francisco

Fuente: https//archivosanfrancisco.wordpress.com

reconoce como "la más pasadista", señala que el acaparamiento de la gloria de Palma dentro de esa tendencia reverente y apologética la empequeñece y deforma, pues ella es "absolutamente peculiar y característica, en su totalidad y en su espíritu, de la académica clientela de la casta feudal". Y más adelante, al referirse a los conservadores Pardo y Lavalle, expresa que ellos son nostálgicos y llenos de unción cuando evocan a la Colonia, en cambio Ricardo Palma la reconstruye "con un realismo burlón y una fantasía irreverente y satírica” (Mariátegui, 1928: 245).

\section{El asalto a la Biblioteca Nacional}

El 13 de febrero de 1912 el gobierno nombró Conservador de la Biblioteca Nacional al poeta arequipeño Percy Gibson, en reemplazo de Clemente Palma - escritor y director de la revista "Variedades" - quien casi cerca de veinte años trabajó en la biblioteca al lado de su padre, el tradicionista. En realidad este despido arbitrario se debió a algunas críticas políticas 
escritas por Clemente en sus editoriales de cada semana, que encolerizaron al presidente Augusto B. Leguía. El suceso ocasionó la renuncia de Ricardo Palma a la institución a la cual había entregado sus mejores esfuerzos, y escribió entonces sus Apuntes para la historia de la Biblioteca de Lima en donde hace el recuento a partir de dos momentos definidos: "el cómo y por qué fui a la Biblioteca" y "cómo y por qué salí de la Biblioteca". El gobierno colocó en su reemplazo a Manuel González Prada, el famoso autor de Pájinas libres, quien al recibir su plaza de director escribió una detallada pero fustigante Nota informativa acerca de la Biblioteca Nacional, en la cual reitera su ácida crítica hacia el ilustre tradicionista. Por ejemplo, al pasar revista de las secciones que contiene la Biblioteca lo hace en forma negativa para dejar mal parado a su antecesor:

Exclusivamente, hay "Salón América” y "Salón Europa", como si no hubiera autores en Asia, en África ni en Oceanía. En el América abundan las obras de europeos, en el Europa no faltan las de americanos. La sección Perú contiene libros de relación muy remota con nuestro país: suele bastar que un autor consagre unas cuantas líneas al Tahuantinsuyo para quedar instalado en anaquel de autores nacionales. Habrían tenido derecho de peruanización Lachatre por su Diccionario y Reclus por su Geografía (Sánchez, L. A. 1986:371).

La costumbre del tradicionista de escribir notas en los márgenes o el hacer subrayados en los textos, también pusieron en guardia al celoso conservador de libros:

Escollos y apostillas hormiguean en los textos, así como anotaciones en antiportadas, portadas y colofones, sin la menor piedad a la nitidez de la impresión ni a la hermosura del grabado. Libros de gran mérito llevan enmendaduras, tarjaduras y borroneaduras. Si las anotaciones a las obras de la Biblioteca Nacional contuvieran censuras de buena ley o 
datos para ilustrar y conducir al lector, se aminoraría en algo la falta; ¿pero qué encierran por lo general? Enmiendas a los textos, juicios no muy benévolos, inexactitudes, falsedades, contradicciones, futesas, desfogues personales y hasta cacografías. Parecen comunicados de periódicos, servidos en dosis homeopática. (Palma, Ob. cit., p. 376)

Cabe anotar que gran parte de los libros que pasaron por la mano de Palma fueron obsequiados por él a la biblioteca. También cabe destacar que esas notas marginales son hoy un rico venero para estudiar con interés su postura como crítico literario. Para González Prada, esto significaba una afrenta que desconocía los límites de la legalidad. Pero, como bien escribiría Teodoro Hampe Martínez en su artículo "Nuevo asedio al bibliotecario mendigo: Ricardo Palma en la Biblioteca Nacional": "Talcomportamiento, junto con el hecho de que a menudo escribiera su nombre en los libros, muestra que Palma

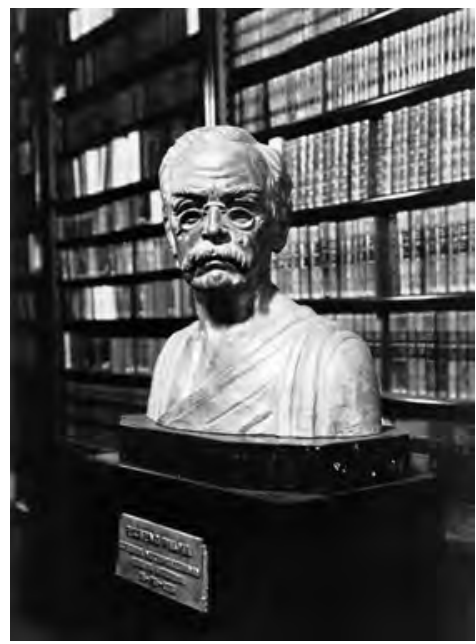

Fig.5.

La estatua de Don Ricardo Palma y al fondo su biblioteca

Fuente: http://miscelanea-rafo. blogspot.pe/2012/09/palmaescritorbibliotecario-y.html debía de alguna manera sentir que la Biblioteca Nacional era suya propia. Incluso la llamó repetidamente "mi hija"'?.

Esto también lo expresa el propio hijo -Clemente- con palabras que, exceptuando la incisiva alusión a González Prada, proyectan de manera ejemplar el legado de su padre:

7 Revista "Aula Palma” $N^{\circ}$ X, pp. 215-216. 
Sí, mi padre ha amado a la Biblioteca como cosa suya, como un bien personal, como una hija, como no la querrá jamás el señor González Prada que, próximo ya a septuagenario, no puede abrigar calor en el alma para un nuevo amor. El alma de mi padre está allí, en esos salones, y aunque el señor González Prada borre sellos, aunque rechine los dientes de furor morboso y palidezca de impotencia, aunque realice todas las transformaciones que le sugiera la rabia, siempre será el señor González Prada un huésped en la Biblioteca, y el espíritu de mi padre irradiado desde su modesto retiro de Miraflores, se sentirá siempre en ese viejo solar de nuestra cultura (L. A. Sánchez, 1986: 418).

En la tercera serie de sus Tradiciones, Ricardo Palma escribiría la siguiente "Cháchara" o introducción lírico-picaresca, en donde deja sentada su impronta tanto literaria como vital:

iOh! Dejadme vivir con las fantásticas

o reales memorias de otra edad,

y mamotretos compulsar solícito,

y mezclar la ficción con la verdad.

(...)

Que en siglo presente los pretéritos

siempre irán en consorcio el bien y el mal,

y si en estos de malo hubo muchísimo,

en el otro de bueno mucho no hay.

(...)

$\mathrm{Ni}$ aguardo que a mis nietos algún dómine

ha de enseñar el Christus abecé

en mis libros, y digan los muy títeres:

-iVaya, mucho hombre nuestro abuelo fue!

Mis libros piedrecillas son históricas 
que llevo de la patria ante el altar.

He cumplido un deber. Saberlo bástame.

Otros vendrán después: -Mejor lo harán. (Palma, 1951: 4).

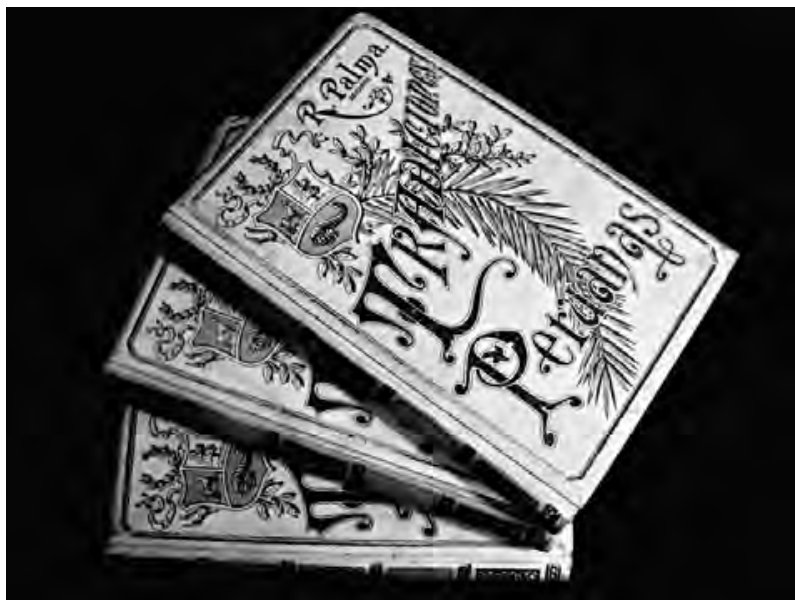

Fig. 7.

“Tradiciones Peruanas" el libro más conocido del prestigioso escritor Fuente: http://fondodocumentallv.com.ar/homenaje-al-escritor-ricardo-palma-enla-biblioteca-de-sarmiento-y-esmeralda/

\section{La herencia del 'Bibliotecario mendigo'}

A un año de cumplirse el centenario del fallecimiento de Palma, el inmenso y valiosísimo legado del "Bibliotecario mendigo" trasciende espacios visibles, tiempos, coyunturas y pormenores, y se convierte en esencial mandato moral, ideal ineludible para todos los peruanos a los cuales impele a descubrir su país y a descubrirse ellos mismos a través del caudal de la cultura. El libro será entonces, en su memoria, la lumbre refulgente y la herramienta veraz para desnudar todos los ropajes. Estamos unidos al libro con indestructible cordón vital, pareciera decirnos el tradicionista. En tal perspectiva, el hombre sería el "libro" o, mejor, "su propio 
libro". Más allá de cualquier contingencia, irrenunciablemente se ha de alzar el "libro-hombre", humeando hacia el futuro y la eternidad, como él escribió en el siguiente poema:

El libro es el sublime

sulfato del espíritu;

por él el genio osado

de un más allá va en pos.

El libro es una antorcha

que el caos ilumina;

eléctrica cadena

que al hombre une con Dios.

iDescúbrete poeta!

Templo es la Biblioteca.

Aquí tu pensamiento

dé culto al ideal.

El libro no es cadáver

que tiene por mortaja

el polvo de los siglos...

El libro es inmortal.

("En la Biblioteca”) $)^{8}$

8 Compton, 2000: 536. 


\section{Bibliografía}

ÁlVAREZ Brun, F. (2000). Miraflores y Ricardo Palma. Discurso de incorporación. Lima: Instituto Ricardo Palma.

COMPTON, M. (2000). Obra poética de Ricardo Palma. Lima: Biblioteca Nacional del Perú.

MARIÁTEGUI, J. C. (1928). 7 ensayos de interpretación de la realidad peruana. Lima: Biblioteca Amauta.

PALMA, R. (1912). Apuntes para la historia de la Biblioteca de Lima. Lima: Empresa Gráfica Unión.

(1951). Tradiciones Peruanas, Tomos II, III y VI. Lima: Editorial Cultura Antártica S.A.

(2005-2006). Epistolario General (1846-1891; 1892-1904; 1905-1919). Lima: Universidad Ricardo Palma.

SÁNCHEZ, L. A. (1986). Manuel González Prada. Obras, Tomos I y II. Lima: Ediciones COPÉ.

Aula Palma (2011), № X. Lima: Universidad Ricardo Palma.

Amauta (1926), № 4. Lima: Biblioteca Amauta.

Recibido el 4 de enero del 2018 Aceptado el 1 de febrero del 2018 